\title{
Nutrition education of young women
}

\author{
BY GILL A. FINE ${ }^{1}$, D. M. CONNING ${ }^{*}$, CELIA FIRMIN ${ }^{2}$, ANNE E. DE LOOY ${ }^{3} \dagger$, \\ M. S. LOSOWSKY ${ }^{4}$, I. D. G. RICHARDS AND JOHN WEBSTER ${ }^{6}$ \\ ${ }^{1}$ British Nutrition Foundation, High Holborn House, 52-54 High Holborn, London WCIV 6 RQ \\ ${ }^{2}$ The General Infirmary at Leeds, Belmont Grove, Leeds LS2 9 NF \\ ${ }^{3}$ Leeds Polytechnic, Calverley Street, Leeds LSI $3 H E$ \\ ${ }^{4}$ Department of Medicine, University of Leeds, St James' University Hospital, Leeds LS9 7TF \\ ${ }^{5}$ Division of General Practice and Public Health Medicine, University of Leeds, 32 Hyde Terrace, \\ Leeds LSI $3 H E$ \\ ${ }^{6}$ School of Mathematics and Computing, Leeds Polytechnic, The Grange, Beckett Park, \\ Leeds LS6 $3 Q X$
}

(Received 12 August 1991-Revised 31 August 1993-Accepted 14 September 1993)

\begin{abstract}
White women aged 25-34 years ( $n$ 264) from the lower socio-economic classes (C2, D and E) were classified according to their motivation in respect of health and their educational attainment and arithmetical ability. They were randomly allocated to three groups. One group (test) was given a course in basic nutrition consisting of a video and booklet, each embellished with motivational material. Those classed as of low ability also received the training material in simplified format. A second group (control) received a video and booklet with no motivational or simplified materials. The third group (baseline) received no tuition and represented a control of publicly available information during the period of the experiment. The participants answered a series of questions by administered questionnaire to measure their nutritional knowledge before and one week after they viewed the video programme. All participants achieved significantly higher scores at the second questionnaire. The test and control groups achieved significantly higher scores than the baseline group but there was no significant difference between the test and control groups. The presentation of motivational or simplified materials had no significant effect on learning ability though those classified as more highly motivated and of higher ability achieved higher scores at each questionnaire. The results indicate that young adult females can be taught basic nutrition irrespective of their motivation or ability.
\end{abstract}

Nutrition education: Motivation: Learning ability

The influence of diet on health status has been the subject of much comment in recent years. In the UK there have been two seminal reviews of the available data. The first was the National Advisory Committee on Nutrition Education (1983) document which attempted to define quantitative dietary guidelines in respect of a number of disease entities. The findings resembled closely earlier reports produced by Swedish (Isaksson, 1975) and American (US Senate Select Committee on Nutrition and Human needs, 1977) authorities. The second was the Report of the Committee on Medical Aspects of Food Policy (1984), Diet and Cardiovascular Disease, which dealt only with diet and coronary heart disease.

Both reports made recommendations on the education of the general population about eating habits. Efforts towards this goal have generally taken the form of simple rules or guidelines issued by health education authorities and industry, the latter through advertising and company booklets. Success has been mixed. For example, although the

\footnotetext{
* For reprints.

$\uparrow$ Present address: Queen Margaret College, Edinburgh.
} 
polyunsaturated fatty acids : saturated fatty acids $(\mathrm{P}: \mathrm{S})$ ratio has on average increased, total fat consumption remains unchanged at $42 \%$ of dietary energy. The consumption of wholemeal bread and white meat has increased but that of fruit and vegetables has remained static (National Food Survey, 1988).

There is evidence that most consumers are unable to effect the practical achievement of even simple dietary goals (Gregory et al. 1990). One reason for this might be that little attempt has been made to explain the nutritional basis of the 'healthy eating' guidelines. As a consequence, the objective, improved nutrition, has not been founded on an understanding of the rationale of dietary modification.

It has been suggested that knowledge of nutrition has no effect on dietary behaviour (Shepherd \& Stockley, 1987) but this study gauged such knowledge by the responses to two questions concerning foods that contained fibre and fat and one concerning energy requirements. These questions are more likely to measure awareness of healthy eating publicity than basic nutrition knowledge. Other studies have demonstrated that active nutrition education influences food choice during the education programme but the effects are not sustained in the long term (Edwards et al. 1985; Ernst et al. 1986). These studies did not attempt to measure the degree of improvement in nutritional knowledge, and, again, the effect on food choice was related more to the role of certain nutrients in provoking disease than to the basic principles of a good diet. It is possible, therefore, that the failure to achieve a longer-term effect on food choice is related to a continued lack of understanding of nutritional and dietary matters.

A proper study of the role of nutrition education on dietary behaviour requires that an effective educational programme is devised followed by a study to determine the impact of such a programme on food choice.

The study reported here was undertaken to determine whether the elements of basic nutrition can be taught to individuals who have no previous specialist knowledge and whether such tuition is more successful if the teaching material is related to the ability of the individual to understand and to motivational factors that might stimulate learning. Later research will examine whether knowledge of basic nutrition facilitates dietary modification where necessary.

\section{MATERIALS AND METHODS}

\section{Subjects}

A group of 264 white women, aged 25-34 years, drawn from socioeconomic classes C2, D and E, living in Leeds were selected from a group of several hundred who agreed to be interviewed after door-to-door recruitment. Representatives of these classes were chosen because they are thought to be most vulnerable to the adverse effects of poor nutrition (Rose \& Marmot, 1981). The study was conducted between April 1989 and December 1990. The revised statistical analysis was not completed until May 1992.

The socioeconomic class was determined using the Office of Population Censuses and Surveys (1980) criteria. This classification provides six classes: A, higher managerial and professional; B, lower managerial; C1, skilled non-manual; C2 skilled manual; D, partially skilled manual; E, unskilled manual.

Selection of participants was by means of a questionnaire administered by a trained interviewer in the home of the potential recruit. The purpose of the questionnaire was threefold: (1) to acquire enough demographic information to determine socioeconomic status, age etc; (2) to permit classification in respect of ability and of motivation (see below); and (3) to measure the extent of nutritional knowledge. The nutrition questions were interposed randomly among the other questions but are listed in Table 1. 
Table 1. Nutrition questions asked during the survey of nutrition education amongst young women*

\begin{tabular}{lc}
\hline \multicolumn{1}{c}{ Question } & Score \\
\hline 1. Name two foods good for protein & 2 \\
2. Name one good protein food for vegetarians & 1 \\
3. Why do we need protein? & 2 \\
4. Is starch a mineral, protein or carbohydrate? & 1 \\
5. What is the carbohydrate in grapefruit juice? & 1 \\
6. What are the units to measure energy? & 1 \\
7. How many calories are needed by a 30-year-old woman? & 2 \\
8/9. (Two simple arithmetical calculations) & 1 \\
10. Recommended intake of energy from fat & 2 \\
11. Name two types of fatty acids & 2 \\
12. Name two good sources of saturated fats & 2 \\
13. Name two good sources of unsaturated fats & 2 \\
14. What are the sources of vitamin D? & 1 \\
15. Which mineral is needed for healthy blood? & 1 \\
16. Which mineral is needed for healthy bones and teeth? & 1 \\
17. Which vitamin helps the absorption of iron? & 2 \\
18. Name two foods good for iron & 1 \\
19. Why do we need dietary fibre? & 2 \\
20. Name two good sources of dietary fibre & 2 \\
21. Why does the body need energy? & 1 \\
22. What are the consequences of taking too much energy? & 3 \\
23. Name the nutrients that provide energy & 2 \\
24. Select two items providing the most energy & 36 \\
Total &
\end{tabular}

* For details, see p. 790.

Table 2. Number of participants in each experimental cohort and each ability/motivation group during a survey of nutrition education amongst young women*

\begin{tabular}{llccccc}
\hline \hline & & \multicolumn{5}{c}{ Group } \\
\cline { 3 - 5 } & Cohort & LMLA & LMHA & HMLA & HMHA & Total \\
\hline & Baseline & 27 & 22 & 14 & 28 & 91 \\
& Control & 28 & 20 & 16 & 23 & 87 \\
& Test & 18 & 18 & 20 & 30 & 86 \\
& Total & 73 & 60 & 50 & 81 & 264 \\
\hline
\end{tabular}

LMLA, low motivation and low ability, LMHA, low motivation and high ability; HMLA, high motivation and low ability; HMHA, high motivation and high ability.

* For details, see pp. $790-793$.

\section{Experimental design}

Each participant was assigned to one of four groups: low motivation and low ability (LMLA); high motivation and low ability (HMLA); low motivation and high ability (LMHA); high motivation and high ability (HMHA). The individuals in each category were allocated randomly to three cohorts designated baseline, control and test cohorts. Each cohort thus contained four groups classified according to motivation and ability 
Tabie 3. Questions and scores used to determine motivation during a survey of nutrition education amongst young women*

\begin{tabular}{|c|c|c|}
\hline Question & & Possible score \\
\hline \multirow[t]{5}{*}{ 1. Cigarette smoking } & 0 & 5 \\
\hline & $<5$ & 3 \\
\hline & $5-9$ & 2 \\
\hline & $10-19$ & $\bar{l}$ \\
\hline & $20+$ & 0 \\
\hline \multirow[t]{5}{*}{ 2. Alcohol (units/week) } & $<5$ & 5 \\
\hline & $6-10$ & 4 \\
\hline & $11-14$ & 3 \\
\hline & $15-20$ & 1 \\
\hline & $21+$ & 0 \\
\hline \multirow[t]{4}{*}{ 3. Exercise (h/week) } & $3+$ & 5 \\
\hline & $1-3$ & 4 \\
\hline & Up to 1 & 3 \\
\hline & 0 & 0 \\
\hline \multirow[t]{4}{*}{ 4. Interest in food } & Very & 5 \\
\hline & Quite & 4 \\
\hline & Not very & 2 \\
\hline & Not at all & 1 \\
\hline \multirow{4}{*}{ 5. Food affects health } & Agrec ++ & 5 \\
\hline & Agree + & 4 \\
\hline & Disagree + & 2 \\
\hline & Disagree $t+$ & 1 \\
\hline \multirow[t]{2}{*}{ 6. Vitamin supplements } & Taken & 5 \\
\hline & Not taken & 0 \\
\hline \multirow[t]{4}{*}{ 7. Interested in learning about food } & Very & 5 \\
\hline & Quite & 4 \\
\hline & Not very & 2 \\
\hline & No interest & 1 \\
\hline \multirow[t]{3}{*}{ 8. Labelling awareness } & Aware and read & 5 \\
\hline & Aware but don't read & 3 \\
\hline & Not aware & 0 \\
\hline \multirow[t]{6}{*}{ 9. Considered health and weight when choosing food } & Both always & 5 \\
\hline & One always & 4 \\
\hline & Both sometimes & 3 \\
\hline & One sometimes & 2 \\
\hline & One rarely & 1 \\
\hline & One never & 0 \\
\hline \multirow[t]{4}{*}{ 10. Attention to food programmes and articles } & 2 or more regularly & 5 \\
\hline & Occasionally & 3 \\
\hline & Rarely & 2 \\
\hline & Never & 0 \\
\hline \multirow[t]{6}{*}{ 11. Whether dieted for weight reasons } & Dieted and successful & 5 \\
\hline & No but weight alright & 4 \\
\hline & Dieted and failed & 3 \\
\hline & Not dieted and weight not normal & 2 \\
\hline & Not dieted and overweight & 1 \\
\hline & Not dieted and obese & 0 \\
\hline
\end{tabular}

* For details, see p. 793.

(Table 2). These groups have also been recombined, for analysis as high motivation (HM), low motivation (LM), high ability (HA) and low ability (LA). These have been designated 'subgroups'.

A large number of interviews was required in order to ensure that there were enough 


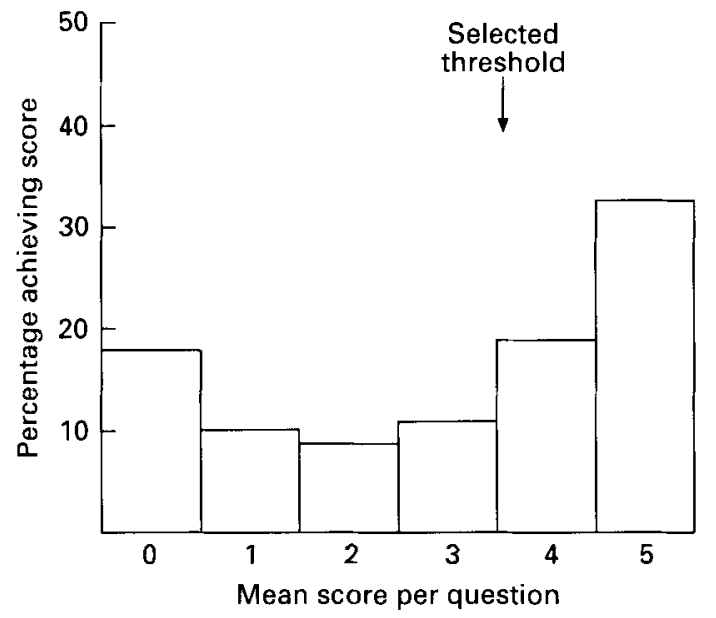

Fig. 1. The distribution of motivational scores of the study population. The selected threshold placed approximately half the participants in the high-motivation subgroup and half in the low-motivation subgroup. For details, see p. 793.

participants in each group for statistical analysis. It proved particularly difficult to find participants of high motivation and low ability using the established definitions.

\section{Motivation}

Eleven questions were used to determine motivation and a scoring system was devised (Table 3). The questions were designed to measure how far interest in the role of diet in promoting health positively influences lifestyle and to determine the presence of other behavioural indicators (smoking, drinking, exercise) interpreted as negative influences.

The maximum possible score (high motivation) was 55 points. The distribution of scores (Fig. 1) shows that approximately $52 \%$ of the participants scored an average of 4 or 5 points per question. The threshold chosen placed approximately half the participants in the high- and half in the low-motivation subgroups.

\section{Ability}

Seven questions were used and a scoring system on a scale 1-5 was devised (Table 4). The questions were designed to gauge educational status and simple arithmetical ability. The maximum possible score was 35 points. The distribution of scores (Fig. 2) shows a clear polarity. The threshold was set so that approximately $50 \%$ of participants were placed in the high-ability subgroup.

\section{Educational materials}

Four types of educational material were produced.

(1) A coloured booklet, entitled Food, What's In It For You?, which conveyed basic facts on energy requirements, nutrient groups, food composition (sources of nutrients) and minimal information on diet and disease.

(2) A coloured pamphlet in the form of a 'news-sheet' which repeated several nutritional 'messages' in the context of motivating influences. These included health (exercise and sport and the avoidance of heart disease), pregnancy and childhood, the elderly and body image. 
Table 4. Questions to determine ability of young women during a survey of nutrition education*

\begin{tabular}{lll} 
& & Possible score \\
\hline 1. Correct use of height-weight chart & Correct & 5 \\
& Incorrect & 0 \\
2. Age at which subject left full-time education & $14-15$ & 0 \\
(years) & 16 & 1 \\
& $17-18$ & 3 \\
& $19-20$ & 4 \\
Qualifications & $21-22+$ & 5 \\
& None & 0 \\
& CSE(s) & 1 \\
& O Levels 1-2 & 2 \\
& O Levels 3-4 & 3 \\
& O Levels 5+ & 4 \\
4. Four simple arithmetical calculations & A Levels & 5 \\
each scoring: & Correct & 5 \\
& Incorrect & 0 \\
\hline
\end{tabular}

* For details, see p. 793.

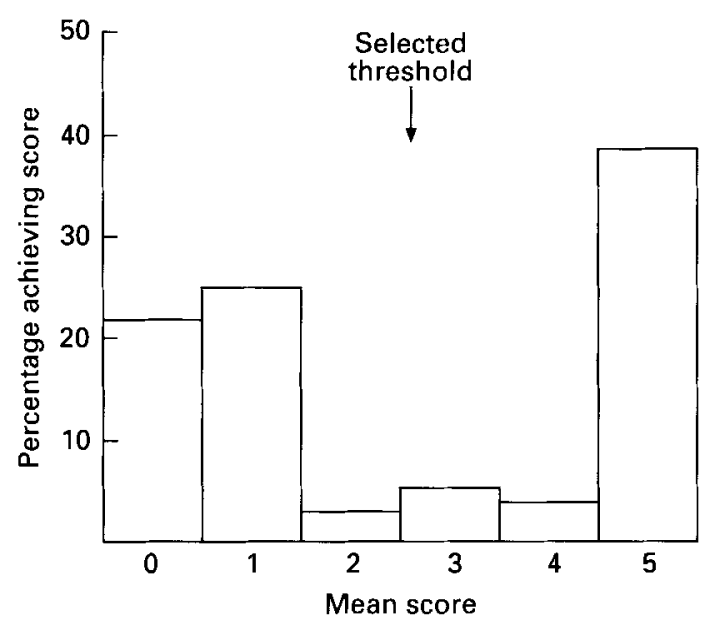

Fig. 2. The distribution of ability scores of the study population. The selected threshold placed approximately half the participants in the high-ability subgroup and half in the low-ability subgroup. For details, see p. 793.

(3) A coloured poster which repeated the factual contents of the booklet in a simplified format intended to be more readily understood by those of lesser ability.

(4) Two video programmes. The main video (the test video) dealt with the factual material used as the basis for the course but included material intended to reflect motives the viewer might have. This video included scenes depicting family life, children and old people, purposeful exercise, adverse health situations and body image which were intended to stimulate a sense of responsibility for the nutritional welfare of others, or personal concerns about health and body image. The script was written and performed by a professional entertainer (Mr Johnny Ball). 
A second video (the control video) was made by editing out the motivational material from the test video. The main theme of both videos concerned individual variation in nutritional requirements, shopping for a variety of foods, preparation of meals and a comparison of energy and nutrient contents of different foods.

\section{Methods}

The potential participants were contacted by 'doorstep' invitation and interviewed in their homes. After the first interview those selected for participation were invited to view the appropriate video individually at a convenient location. Transport was provided to and from the location and a creche made available if required. After viewing the video the participants were provided with the appropriate written material. They were promised a gift voucher $(\mathfrak{£ 7 . 5 0 )}$ ) on completion of the study.

The baseline group did not see the video or receive any written material. This group was included to determine whether changes in nutrition knowledge occurred as a result of publicly available information during the course of the study. Programmes on television and articles in the press were monitored during this period for their relevance to the study.

The control group was shown the control video and received only the basic booklet.

The test group saw the test video and received the booklet and the 'news-sheet' containing motivational material. Those classified as low ability also received the poster displaying the simplified material.

Those who had agreed to take part but then failed to attend the video presentations were assigned as additional participants to the baseline group.

In order to avoid the influence of teacher quality on learning ability no individual tuition was given.

At 1 week after seeing the video, all the participants were again visited at home and that part of the questionnaire containing the nutritional questions was administered. Those who completed this phase were presented with the gift voucher.

\section{Statistical analysis}

The results were analysed on the basis of the differences between the means of the scores obtained at the first and second administrations of the nutritional section of the questionnaires. The analyses concerned the differences between the cohorts, the differences between the groups within each cohort and between comparable groups across the cohorts, and the differences between subgroups within and between cohorts. Statistical evaluation was by analysis of variance and Duncan's multiple range test.

A second analysis, to be published separately, examined the relative efficacy of the educational programme in respect of each question.

\section{RESULTS}

Each cohort showed an increase in knowledge between the first and second administrations of the questionnaire and improvement was achieved by each group within the cohorts (Table 5). The degree of improvement in the test and control cohorts as determined by a comparison of the mean change in score for each cohort was significantly greater than that achieved by the baseline cohort (Table 6). The difference between the control and test cohorts was not significant (Duncan's multiple range test).

Within each cohort, the HM and HA subgroups scored better than the LM and LA subgroups respectively at each questionnaire, but there were no significant differences between the first and second questionnaires for any subgroup. 
Table 5. Mean score differences between cohorts of young women during a survey of nutrition education*

\begin{tabular}{|c|c|c|c|c|c|c|c|c|c|c|}
\hline \multirow[b]{4}{*}{ Cohort } & \multirow[b]{4}{*}{ Group } & \multirow[b]{4}{*}{$n$} & & & \multicolumn{6}{|c|}{ Mean differences } \\
\hline & & & & & \multirow[b]{3}{*}{ Groups } & \multicolumn{5}{|c|}{ Subgroups } \\
\hline & & & \multicolumn{2}{|c|}{ Mean scores } & & \multicolumn{2}{|c|}{ Motivation } & \multicolumn{2}{|c|}{ Ability } & \multirow[b]{2}{*}{ Cohort } \\
\hline & & & $Q_{1}$ & $\mathrm{Q}_{2}$ & & Low & High & Low & High & \\
\hline \multirow[t]{4}{*}{ Baseline } & LMLA & 27 & $10 \cdot 2$ & $12 \cdot 8$ & $2 \cdot 6$ & & & & & \\
\hline & LMHA & 22 & 14.9 & $17 \cdot 6$ & $2 \cdot 7$ & & & & & \\
\hline & HMLA & 14 & $12 \cdot 6$ & $14 \cdot 7$ & $2 \cdot 1$ & $2 \cdot 7$ & 1.85 & $2 \cdot 4$ & $2 \cdot 6$ & 2.465 \\
\hline & HMHA & 28 & $18 \cdot 7$ & $21 \cdot 2$ & $2-5$ & & & & & \\
\hline \multirow[t]{4}{*}{ Control } & LMLA & 28 & $12 \cdot 4$ & 17.9 & $5 \cdot 5$ & & & & & \\
\hline & LMHA & 20 & $14 \cdot 6$ & $20 \cdot 7$ & $6 \cdot 1$ & & & & & \\
\hline & HMLA & 16 & $13 \cdot 6$ & $18 \cdot 9$ & $5 \cdot 3$ & $3 \cdot 8$ & $3 \cdot 2$ & 4.9 & 50 & 5.50 \\
\hline & HMHA & 23 & $18 \cdot 5$ & $23 \cdot 6$ & $5 \cdot 1$ & & & & & \\
\hline \multirow[t]{4}{*}{ Test } & LMLA & 18 & $12 \cdot 9$ & $17 \cdot 1$ & $4 \cdot 2$ & & & & & \\
\hline & LMHA & 18 & $17 \cdot 4$ & $21 \cdot 5$ & $4 \cdot 1$ & & & & & \\
\hline & HMLA & 20 & $15 \cdot 8$ & 21.9 & $6 \cdot 1$ & $4 \cdot 15$ & 52 & $5 \cdot 15$ & $4 \cdot 2$ & 4.675 \\
\hline & HMHA & 30 & $19 \cdot 0$ & $23 \cdot 3$ & $4 \cdot 3$ & & & & & \\
\hline
\end{tabular}

LMLA, low motivation and low ability; LMHA, low motivation and high ability; HMLA, high motivation and low ability; HMHA, high motivation and high ability; Q, questionnaire.

* For details, see pp. 790-795.

Table 6. Statistical analysis (ANOVA) of the results from a survey of nutrition education amongst young women*

\begin{tabular}{|c|c|c|c|c|c|}
\hline Comparison & $\mathrm{df}$ & $\begin{array}{l}\text { Sum of } \\
\text { squares }\end{array}$ & $\begin{array}{c}\text { Mean } \\
\text { square }\end{array}$ & $F$ & $P$ \\
\hline Cohorts (C) & 2 & $411 \cdot 23$ & $205 \cdot 61$ & $15 \cdot 9$ & $<0.001$ \\
\hline \multicolumn{6}{|l|}{ Subgroups } \\
\hline Motivation (M) & 1 & $0 \cdot 17$ & 0.17 & 0.01 & 0.91 \\
\hline Ability (A) & 1 & $3 \cdot 2$ & $3 \cdot 2$ & 0.25 & 0.62 \\
\hline \multicolumn{6}{|l|}{ Interactions } \\
\hline $\mathrm{C} \times \mathrm{M}$ & 2 & 37.56 & $18 \cdot 78$ & 1.45 & $1 \cdot 24$ \\
\hline $\mathrm{C} \times \mathrm{A}$ & 2 & 21.04 & $10 \cdot 52$ & 0.81 & 0.44 \\
\hline $\mathrm{M} \times \mathrm{A}$ & 1 & $10 \cdot 72$ & $10 \cdot 72$ & $0 \cdot 83$ & $0 \cdot 36$ \\
\hline $\mathrm{C} \times \mathrm{M} \times \mathrm{A}$ & 2 & 14.65 & $7 \cdot 32$ & 0.57 & 0.57 \\
\hline Error & 252 & $3259 \cdot 32$ & 12.93 & & \\
\hline
\end{tabular}

* For details, see pp. 790-795.

\section{DISCUSSION}

The method of classification of subjects on motivation allowed a clear separation of individuals with these characteristics and, had they been markedly influential on learning capability, it is likely this would have been detected. High motivation as characterized here was associated with higher scores only when associated with high ability. The characteristics were intended as a measure of the attitude towards a healthy lifestyle with particular emphasis on the role of food. This equates with the model which relates attitude to behaviour as applied to individuals (Ajzen \& Fishbein, 1980) but is used here to determine whether such characteristics influence learning ability. No such influence was detected. 
Similarly, the participants classified as being of high ability consistently outscored those classified as being of low ability but did not demonstrate a significantly greater ability to learn.

There is evidence for a direct relationship between educational attainment and nutritional knowledge (Kushi et al. 1988) and, as was expected, on the ability to learn about nutrition. It is an important distinction that the study reported here assumes no previous knowledge of nutrition. Measures of ability, elementary in nature, were included as a guide to the potential comprehensibility by the individual of this fairly complex subject. The absence of effect throws doubt on the efficacy of the classification used. It remains the case, however, that motivation and ability did not improve learning capability. The interaction of ability as distinct from previous knowledge and attitude has not been assessed in other studies (Ajzen \& Fishbein, 1980) and warrants further investigation.

All three cohorts demonstrated improved nutritional knowledge at the second questionnaire, though the improvement achieved by the control and test cohorts was significantly greater than that of the baseline cohort. The improvement in the baseline cohort, which received no tuition, could have been a response to the stimulus of the first questionnaire or to information appearing in the press and on television. In fact very little nutritional information was released in the daily media during the course of the education programme (though there was a great deal about 'healthy eating'). There may have been more information in the weekly magazines, which were not monitored.

Many studies to explore the relationship between attitudes and food choice have been reported, with variable findings (Shepherd, 1990). A meta-analysis of several studies showed a significant but weak correlation (Axelson et al. 1985). Studies of nutrition awareness and food choice have shown a relationship in respect of certain food products but usually in relation to what is expected to be conducive to good health (Nash, 1990). Studies of the influence of attitudes and beliefs on the ability to learn basic nutrition are conspicuous by their absence.

The highest score possible in the nutrition questionnaire was 36 points. The highest score achieved by an individual was 32 points though the highest mean score was 23.6 points and the greatest improvement was 6 points. This is not a large improvement but is still notable given that the teaching material was largely self administered (no teacher was involved) and there was only a single viewing of the video. It is probable that with more active teaching and reinforcement a greater improvement could be attained. There is evidence also that nutritional knowledge improves if teaching is reinforced with practical demonstrations (Walbeck, 1973).

The present study has demonstrated that it is possible to educate young women from low socioeconomic classes in basic nutrition. The learning capability is not influenced substantially by motivation or ability.

The next phase of the present investigation will be to determine whether individuals who have acquired some elementary knowledge of nutrition are better able to improve their dietary intakes. Before that it will be necessary to evaluate the efficacy of the teaching programmes and define areas where improvements are necessary. This will be the subject of a complementary report.

The authors are grateful to Mr Johnny Ball who wrote and presented the videos, Mr Peter Coltman of the Leeds University Audio Visual Unit who produced the videos, Michael Benn Associates who produced the written materials, Insight Research Ltd who administered the questionnaires, and Mary Ransom for her secretarial support. 


\section{REFERENCES}

Ajzen, I. \& Fishbein, M. (1980). Understanding Attitudes and Predicting Social Behaviour. Englewood Cliffs: Prentice Hall.

Axelson, M. L., Federline, T. L. \& Brinberg, D. (1985). A meta-analysis of food and nutrition-related research. Journal of Nutrition Education 17, $51-54$.

Committee on Medical Aspects of Food Policy (1984). Report of the Panel on Diet in Relation to Cardiovascular Disease. London: H.M. Stationery Office.

Edwards, P. K., Acock, A. C. \& Johnston, R. L. (1985), Nutrition behaviour change: outcomes of an educational approach. Evaluation Review $9,441-459$.

Ernst, N. D., Wu, M., Fiommer, P., Katz, E., Matthews, O., Moskowitz, J., Pinsky, J. L. \& Schreiber, G. B. (1986). Nutrition education at the point of purchase. Preventive Medicine 15, 60-73.

Gregory, J., Foster, K., Tyler, H. \& Wiseman, M. (1990). The Dietary and Nutritional Survey of British Adults. Office of Population Censuses and Surveys. London: H.M. Stationery Office.

Kushi, L. H., Folsom, A. R., Jacobs, D. R., Leupker, R. V., Elmer, P. J. \& Blackburn, H. (1988). Educational attainment and nutrient consumption patterns. Journal of the American Dietetic Association 88, $1203-1236$.

Nash, P. (1990). The influence of nutritional awareness on consumer food choice. British Nutrition Foundation Nutrition Bulletin 15, Suppl. 1, 60-77.

National Advisory Committee on Nutrition Education (1983). Proposals for Nutritional Guidelines for Health Education in Britain. London: Health Education Council.

National Food Survey (1988). Household Food Consumption and Expenditure. London: H.M. Stationery Office.

Office of Population Censuses and Surveys (1980). Classification of Occupation. London: H.M. Stationery Office.

Rose, G. \& Marmot, M. G. (1981). Social class and coronary heart disease. British Heart Journal 45, 13-19.

Shepherd, R. \& Stockley, L. (1987). Nutritional knowledge, attitudes and fat consumption. Journal of the American Dietetic Association 87, 615-619.

Shepherd, R. (1990). Overview of factors influencing food choice. British Nutrition Foundation. Nutrition Bulletin. US Senate Select Committee on Nutrition and Human needs (1977). Dietary Goals for the US. Washington DC: Government Printing Office. 15, Suppl. 1, 12-30.

Walbeck, N. H. (1973). Precepts, paragars and practice: The effects of various methods of nutrition instruction on attitudes, knowledge and behaviour. Journal of Social Psychology 91, 197-205. 